\section{Comparing the Salt Tolerance of Three Landscape Plants Using a Near-continuous Gradient Dosing System}

\author{
Ji Jhong Chen ${ }^{1}$, Yuxiang Wang ${ }^{2}$, Asmita Paudel ${ }^{1}$, \\ and Youping $\operatorname{Sun}^{1}$
}

Additional Index wORDs. gas exchange, Hibiscus syriacus, Physocarpus opulifolius, salinity threshold, Spiraea japonica

SUMMARY. Screening salinity-tolerant plants is usually time intensive and only applicable to a limited number of salinity levels. A near-continuous gradient dosing (NCGD) system allows researchers to evaluate a large number of plants for salinity tolerance with multiple treatments, more flexibility, and reduced efforts of irrigation. Rose of sharon (Hibiscus syriacus), ninebark (Physocarpus opulifolius), and japanese spirea (Spiraea japonica) were irrigated using an NCGD system with eight electrical conductivity (EC) levels ranging from 0.9 to $6.5 \mathrm{dS} \cdot \mathrm{m}^{-1}$. At 11 weeks after irrigation was initiated, there were no significant differences among EC levels in terms of visual score, growth index [(Height + Width $1+$ Width 2$) / 3]$, stem diameter, number of inflorescences, and shoot dry weight (DW) of rose of sharon. However, the root DW, relative chlorophyll content (SPAD), and net photosynthesis rate $\left(P_{n}\right)$ of rose of sharon decreased linearly as EC levels increased. Ninebark and japanese spirea had increased foliar salt damage with increasing EC levels. The growth index, stem diameter, number of inflorescences, shoot and root DW, SPAD, and $P_{n}$ of ninebark decreased linearly as EC levels increased. The growth index and SPAD of japanese spirea decreased quadratically with increasing EC levels, but its stem diameter, number of inflorescences, shoot and root $D W$, and $P_{n}$ decreased linearly with increasing EC levels. The salinity threshold (50\% loss of shoot DW) was 5.4 and $4.6 \mathrm{dS} \cdot \mathrm{m}^{-1}$, respectively, for ninebark and japanese spirea. We were not able to define the salinity threshold for rose of sharon in this study. However, rose of sharon was the most salinity-tolerant species among the three landscape plants.

S alinity negatively affects plants' morphological development and physiological processes. Salinity can cause foliar damage including necrosis, burn, scorch, and premature defoliation (Munns, 2002). Stunted growth, biomass reduction, and inhibited bud formation also happen when plants are grown under salinity stress (Taiz et al., 2015). More resource inputs such as seeds, water, and fertilizers are needed to make up for the loss of plant quality under salinity stress. Physiologically, high concentrations of soluble salts in the soil disturb nutrient uptake, cause protein denaturation, and inhibit plant photosynthesis, stomatal conductance, and biosynthetic processes (Munns and Tester, 2008; Taiz et al., 2015). Specific ions could also accumulate to toxic levels in plant cells.

Salinity tolerance varies among plant species, and selecting salt-tolerant plants and using them in landscapes can be sustainable. Salinity-tolerant plants are usually identified by manually irrigating plants with saline solutions
(Liu et al., 2017; Sun et al., 2015). However, this protocol is time-consuming and only applicable to a limited number of plants. Using automatic irrigation systems, such as a drip injector irrigation system (Aragues et al., 1999), triple-line source sprinkler system (Aragues et al., 1992), and double-emitter source (DES) system (De Malach et al., 1996), can screen multiple plant species for salinity tolerance at a wide range of salinity levels while reducing labor costs. Hawks et al.
(2009) modified the DES system and created an NCGD system with more flexibility, adaptability, and accuracy in delivery capacity. Multiple drip emitters are coupled to provide each plant with nutrient solution and saline solution at a designated ratio but the same total volume. Using the NCGD system to study the responses of different plants to a specific range of salt concentrations can help define the salinity threshold for plant species.

Rose of sharon, ninebark, and japanese spirea are commonly used in urban landscapes in Utah and the Intermountain West United States. According to Liu et al. (2017), the shoot dry weight and leaf area of 'ILVOPS' (Purple Satin ${ }^{\circledR}$ ) rose of sharon was reduced when irrigated with saline solutions at an EC of 5.0 and $10.0 \mathrm{dS} \cdot \mathrm{m}^{-1}$, and plants suffered serious foliar damage when supplied with saline solutions at an EC of 10.0 $\mathrm{dS} \cdot \mathrm{m}^{-1}$. The chlorophyll content of 'ILVOPS' rose of sharon also decreased significantly under irrigation of saline solutions at an EC of 10.0 $\mathrm{dS} \cdot \mathrm{m}^{-1}$. Curtis and Läuchli (1987) found the leaf area of kenaf (Hibiscus cannabinus) reduced when irrigated with saline solutions at an EC of 5.0 and $9.0 \mathrm{dS} \cdot \mathrm{m}^{-1}$. Ninebark showed a poor growth rate when supplied with nutrient solutions at an EC of 2.4 and $2.6 \mathrm{dS} \cdot \mathrm{m}^{-1}$ (Gils et al., 2005). Jull (2009) reported that japanese spirea were moderately tolerant to saline spray. However, in a study conducted by Wang et al. (2019), japanese spirea were moderately sensitive to saline irrigation water with an EC of $6.0 \mathrm{dS} \cdot \mathrm{m}^{-1}$. The thresholds for their salinity tolerance have not been identified. To this end, a greenhouse study was conducted to investigate the responses of these three landscape

\begin{tabular}{llll}
\hline $\begin{array}{l}\text { Units } \\
\begin{array}{l}\text { To convert U.S. to SI, } \\
\text { multiply by }\end{array}\end{array}$ & U.S. unit & SI unit & $\begin{array}{l}\text { To convert SI to U.S., } \\
\text { multiply by }\end{array}$ \\
\hline 100 & $\mathrm{bar}$ & $\mathrm{kPa}$ & 0.01 \\
29.5735 & $\mathrm{fl} \mathrm{oz}$ & $\mathrm{mL}$ & 0.0338 \\
0.3048 & $\mathrm{ft}$ & $\mathrm{m}$ & 3.2808 \\
0.0929 & $\mathrm{ft}^{2}$ & $\mathrm{~m}^{2}$ & 10.7639 \\
0.0283 & $\mathrm{ft}^{3}$ & $\mathrm{~m}^{3}$ & 35.3147 \\
3.7854 & $\mathrm{gal}$ & $\mathrm{L}$ & 0.2642 \\
2.54 & inch $(\mathrm{es})$ & $\mathrm{cm}$ & 0.3937 \\
25.4 & inch $(\mathrm{es})$ & $\mathrm{mm}$ & 0.0394 \\
1 & $\mathrm{mmho} / \mathrm{cm}$ & $\mathrm{dS} \cdot \mathrm{m}^{-1}$ & 1 \\
28.3495 & $\mathrm{Oz}$ & $\mathrm{g}$ & 0.0353 \\
7.4892 & $\mathrm{Oz} / \mathrm{gal}$ & $\mathrm{g} \cdot \mathrm{L}^{-1}$ & 0.1335 \\
1 & $\mathrm{ppm}$ & $\mathrm{mg} \cdot \mathrm{L}^{-1}$ & 1 \\
$\left({ }^{\circ} \mathrm{F}-32\right) \div 1.8$ & ${ }^{\circ} \mathrm{F}$ & ${ }^{\circ} \mathrm{C}$ & $\left({ }^{\circ} \mathrm{C} \times 1.8\right)+32$ \\
& & & \\
\hline
\end{tabular}

Hortlechnology · October 2019 29(5) 
plants to saline irrigation water using an NCGD system to determine their salinity thresholds.

\section{Materials and methods Irrigation system}

An NCGD irrigation system was built in a research greenhouse at the Utah State University (USU) in Logan, UT, following the protocol described by Hawks et al. (2009). Two chemical injectors (model DII6; Dosatron, Clearwater, FL) were connected with irrigation lines that supply nutrient solution and saline solution, respectively. A stock solution of $48 \mathrm{~g} \cdot \mathrm{L}^{-}$ ${ }^{1} 21 \mathrm{~N}-2.2 \mathrm{P}-16.6 \mathrm{~K}$ water-soluble fertilizer (Peters Excel $^{\circledR}$ 21-5-20 MultiPurpose Fertilizer; ICL Specialty Fertilizers, Dublin, $\mathrm{OH}$ ) plus $0.033 \mathrm{~g} \cdot \mathrm{L}^{-1}$ ethylenediaminetetraacetic acid iron (BASF Corp., Research Triangle Park, $\mathrm{NC}$ ) was injected via chemical injector to tap water to deliver a nutrient solution of $161 \mathrm{ppm}$ nitrogen. Another stock solution at $450 \mathrm{~g} \cdot \mathrm{L}^{-1}$ calcium chloride $\left[\mathrm{CaCl}_{2}\right.$ (Hi Valley Chemical, Centerville, UT)] was injected into

Received for publication 12 Apr. 2019. Accepted for publication 28 May 2019.

Published online 21 August 2019.

${ }^{1}$ Department of Plants, Soils, and Climate, Utah State University, 4820 Old Main Hill, Logan, UT 84322

${ }^{2}$ Western Arid Region Grassland Resources \& Ecology Key Lab, Xinjiang Agricultural University, No. 311 East Nongda Road, Urumqi, Xinjiang 830052, China

This research was supported in part by the U.S. Department of Agriculture (USDA) National Institute of Food and Agriculture Hatch project UTA01381, New Faculty Start-Up Funds from the Office of Research and Graduate Studies, the Center for Water-Efficient Landscaping at Utah State University. This research was also supported by the Utah Agricultural Experiment Station, Utah State University, and approved as journal paper no. 9203. We appreciate the financial support from Grassology Peak Discipline Foundation of Xinjiang Uygur Autonomous Region and National Modern Agricultural Technology \& Industry System (CARS-34) of China to Yuxiang Wang as a visiting scholar at Utah State University, Logan.

We are grateful for technical assistance from Samuel Johnson and valuable comments from anonymous reviewers.

The content is solely the responsibility of the authors and does not necessarily represent the official views of the funding agencies. Mention of a trademark, proprietary product, or vendor does not constitute a guarantee or warranty of the product by the USDA and the American Society for Horticultural Science, and does not imply its approval to the exclusion of other products or vendors that also may be suitable.

Y.S. is the corresponding author. E-mail: youping.sun@ usu.edu.

This is an open access article distributed under the CC BY-NC-ND license (https://creativecommons.org/ licenses/by-nc-nd/4.0/).

https://doi.org/10.21273/HORTTECH04385-19 nutrient solution to make a saline solution at $0.52 \% \mathrm{CaCl}_{2}$. Calcium chloride was used in the experiment to mimic the property of highly calcareous soils (Hawks et al., 2009).

The pressure of the irrigation lines was maintained at 20 bar to make emitters function properly. Solenoid valves were installed and controlled using a controller $\left(\mathrm{X}-\mathrm{CORE}^{\circledR}\right.$; Hunter Industries, San Marcos, CA). Commercial emitters (Xeri-Bug emitters and pressure-compensating modules; Rain Bird Corp., Tucson, AZ) at different flow rates were coupled to irrigate plants at an efflux volume of $14 \mathrm{gal} / \mathrm{h}$ of irrigation to achieve respective salinity levels ranging from 0.9 to $6.5 \mathrm{dS} \cdot \mathrm{m}^{-1}$ (Table 1 ).

\section{Plant materials}

Rose of sharon and japanese spirea cuttings were collected at the USU main campus (Logan, UT) on 21 July 2018; ninebark cuttings were collected from USU Innovation Campus (North Logan, UT) on 10 Aug. 2018. Cuttings were treated with plant rooting hormone $[1 \%$ indole-3-butyric acid (IBA) and $0.5 \%$ l-naphthaleneacetic acid; Dip 'N' Grow, Clackamas, OR] at 3000 ppm IBA and stuck in a mixture of $4: 1$ perlite (Hess Perlite, Malad City, ID): Canadian sphagnum peatmoss (Sun Gro Horticulture, Agawam, MA). On 10 Sept., rooted cuttings were transplanted into l-gal injection-molded, polypropylene containers (PC1D-4; Nursery Supplies, Orange, CA). Containers were filled with a soilless growing substrate consisting of $75 \%$ Canadian sphagnum peatmoss, $25 \%$ vermiculite (ThermO-Rock West, Chandler, AZ), and $24.3 \mathrm{~g} / \mathrm{ft}^{3}$ white athletic field-marking gypsum $(92 \%$ calcium sulfate dihydrate, $21 \%$ calcium, 17\% sulfur; Western Mining and Minerals, Bakersfield, CA). All the plants were grown in a greenhouse in Logan, UT (lat. $41^{\circ} 45^{\prime} 28^{\prime \prime} \mathrm{N}$, long. $111^{\circ} 48^{\prime} 47^{\prime \prime} \mathrm{W}$; elevation, $1409 \mathrm{~m}$ ) at a temperature of $25 / 20^{\circ} \mathrm{C}$ day/night and watered with tap water $\left(\mathrm{EC}, 0.311 \mathrm{dS} \cdot \mathrm{m}^{-1}\right.$; $\mathrm{pH}, 8.19$ ) until the experiment started. On 15 Oct., ninebark plants were pruned to 5 inches and the inflorescences were removed.

On 17 Oct., uniform plants were assigned to the salinity levels that the NCGD system provided. Plants were irrigated for 11 weeks, and morphological and physiological data were recorded. Environmental conditions in the greenhouse were at $24.3 \pm$ $2.0^{\circ} \mathrm{C}$ during the day and $21.8 \pm$ $2.7^{\circ} \mathrm{C}$ at night; the daily light integral was $16.7 \pm 7.5 \mathrm{~mol} \cdot \mathrm{m}^{-2} \cdot \mathrm{d}^{-1}$. Abamectin $\left(\right.$ Avid $^{\circledR}$ 0.15EC; Syngenta Crop Protection, Greensboro, NC) at 0.1 $\mathrm{mL} / \mathrm{gal}$ a.i. was sprayed to control aphids (Aphidoidea).

\section{Treatments}

The NCGD irrigation system with eight different salinity levels ( $\mathrm{Ta}-$ ble 1 ) was set to irrigate plants for 1 min each cycle, once per day from 17 Oct. to 17 Nov. 2018, twice per day from 18 Nov. to 20 Dec. 2018, and three times per day from 21 Dec. 2018 to 3 Jan. 2019. The irrigation frequency increased as plants grew bigger. The system was shut down on 4 Jan. 2019. Thereafter, the nutrient solution from the injector was used for irrigation. The ECs of the irrigation solutions from the emitters (Table 1) were measured using an EC meter (SensION5; Hach ${ }^{\circledR}$, Loveland, $\mathrm{CO}$ ) at the initiation (17 Oct. 2018) and termination (16 Jan. 2019) of the experiment. A PourThru protocol (Gibson, 2007) was adopted to collect the EC of leachate solution weekly using the EC meter (LAQUA Twin; Horiba, Kyoto, Japan). In brief, a saucer was placed under the container that drained for at least 30 min immediately after irrigation solution was applied. A total of $100 \mathrm{~mL}$ distilled water was poured on the surface of the substrate to obtain leachate $(\approx 30 \mathrm{~mL})$ in the saucer. One plant per EC level per species was chosen for measurement.

\section{Data collection}

Growth Data. Plant height, stem diameter, and canopy width were recorded at the beginning of the experiment (17 Oct. 2018) and the end of the experiment (16 Jan. 2019). Plant height (centimeters) from the surface of medium to the highest terminal bud was recorded. Canopy width (centimeters) was also measured at perpendicular directions of the canopy. The plant growth index was defined as the average of plant height and two widths [(Height + Width $1+$ Width 2)/3]. Stem diameter (millimeters) was measured using a caliper (Mitutoyo Corp., Kawasaki, Japan). Number of inflorescences of rose of sharon, ninebark, 
Table 1. The emitter combinations for a near-continuous gradient dosing (NCGD) system with eight treatments and the electrical conductivity (EC) of irrigation solution from emitters.

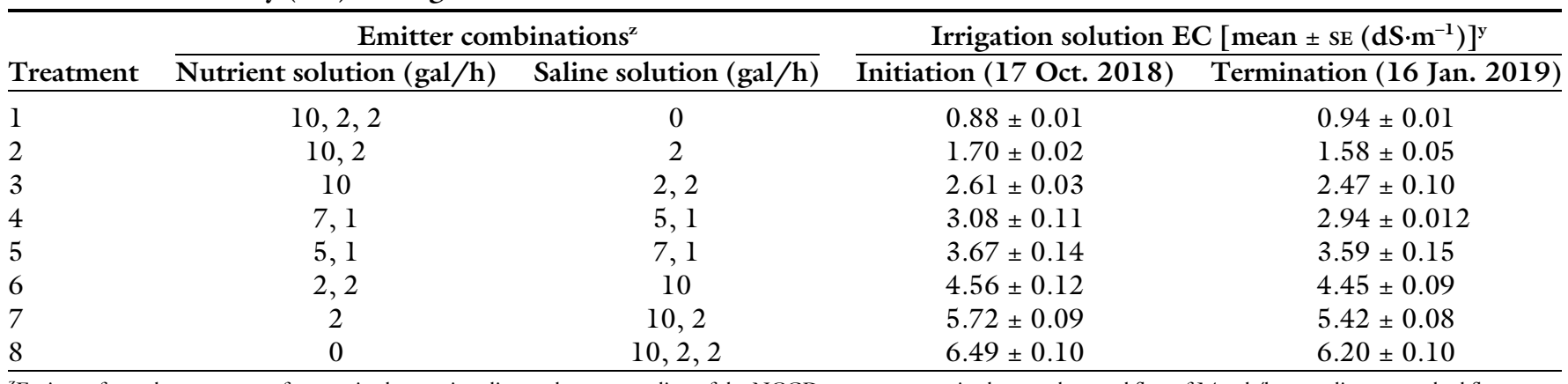

${ }^{\mathrm{z}}$ Emitters from the same manufacturer in the nutrient line and treatment line of the NCGD system were paired to reach a total flux of 14 gal/h according to marked flow rates. Nutrient solution supplied by the nutrient line was made by injecting a stock solution of $48 \mathrm{~g} \cdot \mathrm{L}^{-1} 21 \mathrm{~N}-2.19 \mathrm{P}-16.6 \mathrm{~K}$ water-soluble fertilizer plus $0.033 \mathrm{~g} \cdot \mathrm{L}^{-1}$ of ethylenediaminetetraacetic acid iron to tap water. Saline solution supplied by the treatment line was made by injecting a stock solution of $450 \mathrm{~g} \cdot \mathrm{L}^{-1} \mathrm{CaCl}_{2}$ to the nutrient solution; l gal $=3.7854 \mathrm{~L}, \mathrm{~g} \cdot \mathrm{L}^{-1}=0.1335 \mathrm{oz} / \mathrm{gal}$.

${ }^{\mathrm{y}}$ Leachate EC values of 18 measurements; $1 \mathrm{dS} \cdot \mathrm{m}^{-1}=1 \mathrm{mmho} / \mathrm{cm}$.

and japanese spirea was also counted. Plant shoots were cut at the substrate surface, and shoot DW was measured after drying in an oven at $80{ }^{\circ} \mathrm{C}$ for 7 d. The salinity threshold for each species was calculated as the EC level at which a plant lost $50 \%$ of shoot DW. In addition, roots of all plants irrigated with saline solutions at an $\mathrm{EC}$ of $1.7,3.1,4.6$, and $6.5 \mathrm{dS} \cdot \mathrm{m}^{-1}$ were cleaned and dried in the oven at $80{ }^{\circ} \mathrm{C}$ for $7 \mathrm{~d}$, and root $\mathrm{DW}$ was measured.

Visual SCORE AND CHLOROPHYLL CONTENT. Visual quality was rated biweekly by giving a score to each plant from 0 to 5 , where $0=$ dead, $1=$ severe foliar damage $(>90 \%$ leaves with burn, necrosis, and discoloration), $2=$ moderate foliar damage ( $90 \%$ to $50 \%), 3=$ slight foliar damage $(50 \%$ to $10 \%), 4=$ good quality with minimal foliar damage $(<10 \%)$; and $5=$ excellent without foliar damage (Sun et al., 2015). Relative chlorophyll content of all plants was recorded using a chlorophyll meter (SPAD-502; Minolta Camera Co., Osaka, Japan) l week before harvest. Five mature leaves chosen randomly from each plant were measured, and the averaged value was recorded.

Gas exchange. Gas exchange was taken on a sunny day between 1000 and $1400 \mathrm{HR}$ using a portable photosynthesis system with a PLC3 universal leaf cuvette (CIRAS-3; PP System, Amesbury, MA) l week before harvest. Mature leaves at the outer part of canopy without damage were chosen for gas exchange. Rose of sharon and ninebark plants irrigated with saline solutions at an EC of 1.7, $3.1,4.6$, and $6.5 \mathrm{dS} \cdot \mathrm{m}^{-1}$ were used for the measurements, but japanese spirea plants irrigated with saline solutions at an EC of 0.9, 2.6, 3.7, and $5.7 \mathrm{dS} \cdot \mathrm{m}^{-1}$ were used because all plants died at an EC of $6.5 \mathrm{dS} \cdot \mathrm{m}^{-1}$. The photosynthesis photon flux within the cuvette was 1000 $\mu \mathrm{mol} \cdot \mathrm{m}^{-2} \cdot \mathrm{s}^{-1}$, with $38 \%$ red, $37 \%$ green, and $25 \%$ blue provided from light-emitting diodes, whereas the carbon dioxide $\left(\mathrm{CO}_{2}\right)$ and leaf temperature were set at $400 \mu \mathrm{mol} \cdot \mathrm{mol}^{-1}$ and $25^{\circ} \mathrm{C}$, respectively.

\section{Experiment design and data analysis}

The experiment was a randomized complete block design with eight salinity levels and six irrigation blocks (Hawks et al., 2009). A two-way analysis of variance procedure was used to test the effects of salinity and species on plant growth and gas exchange data. Linear and quadratic trend analysis was performed for all parameters. All statistical analyses were carried out using a generalized linear model in JMP software (version 13.2; SAS Institute, Cary, NC).

\section{Results and discussion}

LeACHATe EC. There was a consistent linear trend of EC values of the solutions generated from the NCGD irrigation system at the initiation and termination of the experiment $\left[r^{2}=\right.$ $0.99(P<0.0001)$ and $r^{2}=0.99(P<$ 0.0001 ), respectively (Table 1$)]$. The EC values of the weekly leachate solutions were well correlated with those of the irrigation water applied for rose of sharon [all $r^{2}<0.97$ (all $P<$ 0.0001 )], ninebark [all $r^{2}<0.70$ (all $P<0.06)$ ], and japanese spirea [all $r^{2}<0.93$ (all $P<0.0007$ )] (data not shown). These results indicated that salinity levels in the substrate were well maintained. Salts might be washed out as high leaching fractions of $62 \%$ and $52 \%$ were recorded for rose of sharon and japanese spirea, respectively. Relatively, more fluctuations in the $\mathrm{EC}$ values of the leachate solutions were observed for ninebark compared with rose of sharon and japanese spirea. This might result from a relatively low leaching fraction of $39 \%$ and fast growth of ninebark.

Visual Quality. Rose of sharon did not show significant foliar salt damage at any salinity levels (Fig. 1A). However, in a previous study, 'Brilliant' chinese hibiscus (Hibiscus rosa-sinensis) was found having foliar salt damage when the salinity level of irrigation water was greater than 5.4 $\mathrm{d} S \cdot \mathrm{m}^{-1}$ (Valdez-Aguilar et al., 2011). Liu et al. (2017) observed that the visual score of 'ILVOPS' rose of sharon irrigated with a saline solution at an EC of $10.0 \mathrm{dS} \cdot \mathrm{m}^{-1}$ differed significantly from that with a saline solution at an EC of 1.2 and 5.0 $\mathrm{dS} \cdot \mathrm{m}^{-1}$ at 5 and 9 weeks, but no significant difference occurred between 1.2 and $5.0 \mathrm{dS} \cdot \mathrm{m}^{-1}$. Therefore, the salinity level to cause foliar salt damage to rose of sharon might be between 5.0 and $10.0 \mathrm{dS} \cdot \mathrm{m}^{-1}$.

Ninebark started to show foliar salt damage 4 weeks after the experiment was initiated. The newly mature leaves of ninebark irrigated with saline solutions at an EC of 5.7 and $6.5 \mathrm{dS} \cdot \mathrm{m}^{-1}$ curled and had necrosis at the leaf margins. At 6 weeks, most ninebark plants irrigated with saline solutions at an EC of 5.7 and 6.5 

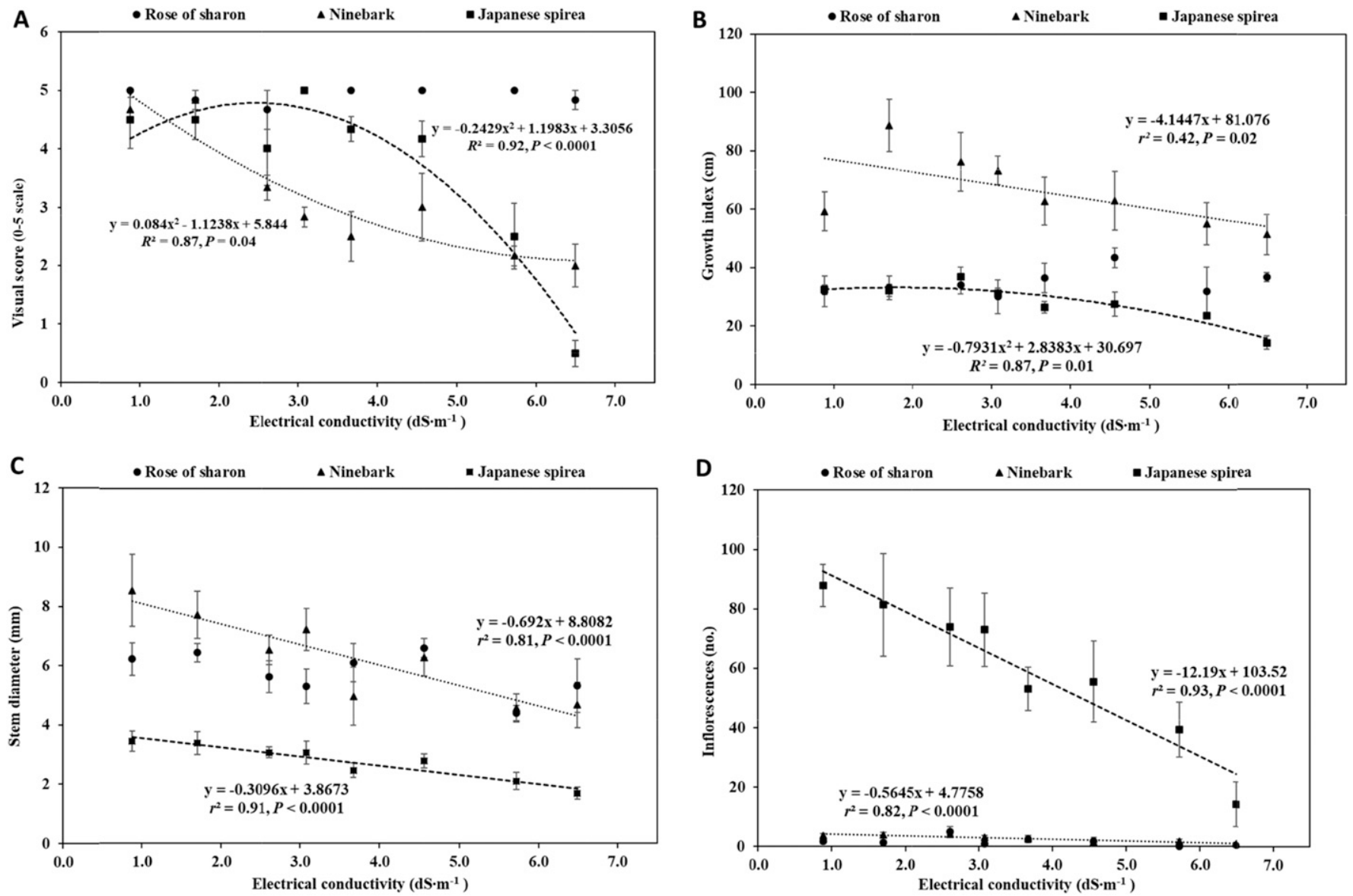

Fig. 1. The visual score (A), growth index (B), stem diameter (C), and number of inflorescences (D) of rose of sharon, ninebark, and japanese spirea irrigated for 11 weeks with saline solutions at eight different electrical conductivity levels using a nearcontinuous gradient dosing system. Visual score reference scale: $0=$ dead, $1=$ severe foliar damage $(>90 \%$ leaves with burn, necrosis, and discoloration), $2=$ moderate foliar damage $(\mathbf{5 0 \%}-\mathbf{9 0 \%}), 3=$ slight foliar damage $(\mathbf{5 0} \%-10 \%), 4=$ good quality with minimal foliar damage $(<10 \%), 5=$ excellent without foliar damage. Growth index $=[($ Height + Width $1+$ Width 2$) / 3]$. Linear and quadratic trend analyses were used; $1 \mathrm{dS} \cdot \mathrm{m}^{-1}=1 \mathrm{mmho} / \mathrm{cm}, 1 \mathrm{~cm}=0.3937 \mathrm{inch}, 1 \mathrm{~mm}=0.0394 \mathrm{inch}$.

$\mathrm{dS} \cdot \mathrm{m}^{-1}$ had $50 \%$ leaves with salt damage (data not shown). At 8 weeks, plants irrigated with saline solutions at an EC of 2.6 to $4.6 \mathrm{dS} \cdot \mathrm{m}^{-1}$ also showed salt damage on the leaves, with more damage at greater salinity levels. Ten weeks after the experiment was initiated, 13 plants were found with moderate to severe foliar salt damage (visual score, $\leq 2$ ) when they were irrigated with saline solutions at an EC of 3.7 to $6.5 \mathrm{dS} \cdot \mathrm{m}^{-1}$. At 11 weeks, visual score decreased quadratically $\left[R^{2}=0.87(P=0.04)\right]$ with increasing EC levels (Fig. 1A). The visual quality of ninebark decreased rapidly at an EC of 0.9 to $4.6 \mathrm{dS} \cdot \mathrm{m}^{-1}$ and became stable at an EC of 5.7 to $6.5 \mathrm{dS} \cdot \mathrm{m}^{-1}$. The salinity threshold for ninebark, calculated using the visual score, was $5.2 \mathrm{dS} \cdot \mathrm{m}^{-1}$, at which $50 \%$ of the leaves were damaged. Gils et al. (2005) reported that ninebark showed mild leaf scorch, brown spots, and blotches on older leaves when supplied with a nutrient solution at an EC of $2.4 \mathrm{dS} \cdot \mathrm{m}^{-1}$ and $25 \%$ of leaves senesced when irrigated with a nutrient solution at an $\mathrm{EC}$ of $2.6 \mathrm{dS} \cdot \mathrm{m}^{-1}$.

Japanese spirea irrigated with saline solutions at an EC of $6.5 \mathrm{dS} \cdot \mathrm{m}^{-1}$ showed burned leaf tips and curled leaves at 4 weeks. At 6 weeks, moderate to severe foliar salt damage ( $>50 \%$ of leaves with salt damage) was found on three plants irrigated with saline solutions at an EC of 6.5 $\mathrm{d} S \cdot \mathrm{m}^{-1}$. At 8 weeks, two plants died and two more plants had $90 \%$ saltdamaged leaves when irrigated with saline solutions at an EC of $6.5 \mathrm{dS} \cdot \mathrm{m}^{-1}$. At 10 weeks, slight-to-moderate salt damage (visual scores, 2-4) was found on japanese spirea plants irrigated with saline solutions at an EC of 4.6 and 5.7 $\mathrm{dS} \cdot \mathrm{m}^{-1}$. The visual score of japanese spirea decreased quadratically $\left[R^{2}=\right.$ $0.92(P<0.0001)]$ with increasing salinity levels at 11 weeks (Fig. 1A). A dramatic decrease in the visual quality of japanese spirea was observed at an EC of 3.7 to $6.5 \mathrm{dS} \cdot \mathrm{m}^{-1}$. Three plants died when irrigated with saline solutions at an EC of $6.5 \mathrm{dS} \cdot \mathrm{m}^{-1}$ for 11 weeks. The salinity threshold for japanese spirea was $3.4 \mathrm{dS} \cdot \mathrm{m}^{-1}$, at which $50 \%$ of leaves were damaged. Based on the calculated salinity thresholds, japanese spirea is more susceptible to salinity stress than ninebark. In the study by Wang et al. (2019), all 'Tracy' and 'Yan' japanese spirea died, whereas $75 \%$ and $25 \%$ of 'NCSX2' and 'Minspi' japanese spirea died, respectively, when they were irrigated with a saline solution at an EC of 6.0 $\mathrm{d} S \cdot \mathrm{m}^{-1}$. However, the visual quality of 'SMNSJMFP' japanese spirea was good, with little foliar salt damage. Marosz (2004) found that 'Grefsheim' spirea (Spiraea Xcinerea) had severe foliar salt damage, with $33 \%$ of plants 
dead at the plots irrigated with sodium chloride $(\mathrm{NaCl})$ solution at an EC of $12.0 \mathrm{dS} \cdot \mathrm{m}^{-1}$, but all plants survived at an EC of $6.0 \mathrm{dS} \cdot \mathrm{m}^{-1}$.

GrowTH InDEx. At 11 weeks, no significant correlation between the growth index of rose of sharon and the salinity levels of irrigation solution was observed in this experiment (Fig. 1B). Liu et al. (2017) also found that plant height of 'ILVOPS' rose of sharon did not change at salinity levels at an EC of 5.0 and $10.0 \mathrm{dS} \cdot \mathrm{m}^{-1}$ at 5 and 9 weeks. The growth index of ninebark decreased linearly with increasing EC levels $\left[r^{2}=0.42(P=0.02)\right.$; Fig. 1B]. Compared with the control (EC, $0.9 \mathrm{dS} \cdot \mathrm{m}^{-1}$ ), the growth index of ninebark plants irrigated with saline solutions at an EC of $6.5 \mathrm{dS} \cdot \mathrm{m}^{-1}$ decreased $\approx 42 \%$. The growth index of japanese spirea reduced quadratically with increasing EC levels $\left[R^{2}=\right.$ 0.87 ( $P=0.01)$; Fig. 1B]. Compared with the control (EC, $0.9 \mathrm{dS} \cdot \mathrm{m}^{-1}$ ), the growth index of japanese spirea plants irrigated with saline solutions at an EC of $6.5 \mathrm{dS} \cdot \mathrm{m}^{-1}$ decreased by $56 \%$. Wang et al. (2019) found that the growth index of japanese spirea decreased by $4 \%$ and $12 \%$ compared with the control $\left(\mathrm{EC}, 1.2 \mathrm{dS} \cdot \mathrm{m}^{-1}\right)$ when irrigated with saline solutions at an EC of 3.0 and $6.0 \mathrm{dS} \cdot \mathrm{m}^{-1}$, respectively. According to Marosz (2004), mean shoot length of 'Grefsheim' spirea reduced by $30 \%$ at an EC of $12.0 \mathrm{dS} \cdot \mathrm{m}^{-1}$ compared with the control $\left(\mathrm{EC}, 0.5 \mathrm{dS} \cdot \mathrm{m}^{-1}\right)$. The results obtained from this study on ninebark and japanese spirea were consistent with previous findings that salinity stunted plant growth (Cai et al., 2014; Sun et al., 2015).

Stem Diameter. No trend was observed for the influence of saline irrigation water on the stem diameter of rose of sharon in our experiment. However, the stem diameter of both ninebark and japanese spirea decreased linearly with increasing EC levels $\left[r^{2}=0.81(P<0.0001)\right.$ and $0.91(P<0.0001)$, respectively; Fig. 1C]. Compared with the control, the stem diameter of ninebark irrigated with saline solutions at an EC of $6.5 \mathrm{dS} \cdot \mathrm{m}^{-1}$ was reduced by $45 \%$ and that of japanese spirea decreased $\approx 51 \%$.

Number of INFLORESCENCES. The number of flowers and flower buds of rose of sharon was unaffected by saline irrigation water in this study (Fig. 1D). However, the number of inflorescences of both ninebark and japanese spirea decreased as the EC levels of saline irrigation water increased. For ninebark, a linear trend $(P<0.0001)$ between EC levels and the number of inflorescences was observed, with a correlation coefficient of 0.82 . The number of inflorescences of ninebark irrigated with saline solutions at an EC of $6.5 \mathrm{dS} \cdot \mathrm{m}^{-1}$ decreased by $73 \%$ compared with the control. For japanese spirea, a linear trend $(P<0.0001)$ between EC levels and the number of inflorescences was found, with a correlation coefficient of 0.93 . The number of inflorescences of japanese spirea irrigated with saline solutions at an EC of $6.5 \mathrm{dS} \cdot \mathrm{m}^{-1}$ was reduced by $84 \% \mathrm{com}-$ pared with the control. In a study by Marosz (2004), the number of inflorescences for 'Grefsheim' spirea decreased by $89 \%$ to $92 \%$ when irrigated with a saline solution at an EC of $12.0 \mathrm{dS} \cdot \mathrm{m}^{-1}$ compared with saline solutions at an EC of 0.5, 1.5, 3.0, and $6.0 \mathrm{dS} \cdot \mathrm{m}^{-1}$. Wang et al. (2019) also reported the number of inflorescences of 'Galen', 'Minspi', and 'SMNSJMFP' japanese spirea reduced by $39 \%$ to $50 \%$ when irrigated with a saline solution at an EC of 6.0 $\mathrm{dS} \cdot \mathrm{m}^{-1}$. A reduction in the number of flowers and/or inflorescences has been reported in a variety of plant species (Cai et al., 2014; Sun et al., 2015). This might result from high concentrations of specific ions in plants that inhibited the initiation of flower buds (Taiz et al., 2015).

Sнoot DW. The shoot DW of rose of sharon was not influenced by saline irrigation water during the experiment (Fig. 2A). Liu et al. (2017) also observed that the shoot DW of 'ILVOPS' rose of sharon did not change when they were irrigated with saline solutions at an EC of $5.0 \mathrm{dS} \cdot \mathrm{m}^{-1}$ for 5 and 9 weeks, but reduced significantly at an EC of $10.0 \mathrm{dS} \cdot \mathrm{m}^{-1}$. The shoot DW of kenaf was also reduced when irrigated with a $\mathrm{NaCl}$ solution at an EC of $9.0 \mathrm{dS} \cdot \mathrm{m}^{-1}$, but did not change at an EC of $5.0 \mathrm{dS} \cdot \mathrm{m}^{-1}$ (Curtis and Läuchli, 1987). Valdez-Aguilar et al. (2011) reported that stem and leaf DWs of 'Brilliant' chinese hibiscus decreased when EC levels of irrigation water increased from 0.6 to 12.0 $\mathrm{dS} \cdot \mathrm{m}^{-1}$. The salinity threshold for rose of sharon might be greater than 6.5
$\mathrm{dS} \cdot \mathrm{m}^{-1}$, which is the greatest salinity level provided by the NCGD system.

The shoot DW of ninebark and japanese spirea decreased linearly with increasing EC levels $(P<0.0001$; Fig. 2A). Ninebark and japanese spirea lost $50 \%$ of biomass when irrigated with saline solutions at an EC of 5.4 and $4.6 \mathrm{dS} \cdot \mathrm{m}^{-1}$, respectively. This result indicates that ninebark was more tolerant to salinity stress than japanese spirea. Similarly, japanese spirea was moderately sensitive to saline irrigation water at an EC of 6.0 $\mathrm{dS} \cdot \mathrm{m}^{-1}$, with a $35 \%$ to $56 \%$ lower shoot DW than at an EC of 1.2 $\mathrm{dS} \cdot \mathrm{m}^{-1}$ (Wang et al., 2019). However, Marosz (2004) reported that the fresh weight of 'Grefsheim' spirea reduced by $70 \%$ to $78 \%$ when irrigated with saline solutions at an EC of $12.0 \mathrm{dS} \cdot \mathrm{m}^{-1}$ compared with an EC of $0.5,1.5,3.0$, and $6.0 \mathrm{dS} \cdot \mathrm{m}^{-1}$. The threshold for $50 \%$ loss of fresh weight of 'Grefsheim' spirea was between EC of 6.0 and $12.0 \mathrm{dS} \cdot \mathrm{m}^{-1}$, which is greater than that in our study.

Root DW. The root DW of rose of sharon, ninebark, and japanese spirea decreased linearly as the EC levels of saline irrigation water increased (Fig. 2B). The root DW of rose of sharon, ninebark, and japanese spirea irrigated with saline solutions at an EC of $6.5 \mathrm{dS} \cdot \mathrm{m}^{-1}$ was reduced by $39 \%$, 85\%, and $89 \%$, respectively, compared with those at an EC of $1.7 \mathrm{dS} \cdot \mathrm{m}^{-1}$. 'Brilliant' chinese hibiscus also had reduced root DW when irrigated with saline solutions at an EC of 0.6 to $12.0 \mathrm{dS} \cdot \mathrm{m}^{-1}$ (Valdez-Aguilar et al., 2011). It was reported that plants can acclimate to salinity stress by increasing the root-to-shoot ratio to increase water uptake and limit water loss (Acosta-Motos et al., 2017). In our study, the root-to-shoot ratio of three species decreased linearly with increasing EC levels $(P=0.002$ and $P<0.0001$ for ninebark and japanese spirea, respectively), but not for rose of sharon (data not shown). The ninebark irrigated with a nutrient solution at an EC of 2.4 or $2.6 \mathrm{dS} \cdot \mathrm{m}^{-1}$ was found to decrease the root-to-shoot ratio compared with irrigation water at an EC of $1.7 \mathrm{dS} \cdot \mathrm{m}^{-1}$ (Gils et al., 2005). However, the root-to-shoot ratio of 'Brilliant' chinese hibiscus did not change with EC levels increasing from 0.6 to 12.0 $\mathrm{dS} \cdot \mathrm{m}^{-1}$ (Valdez-Aguilar et al., 2011).

Chlorophyll content. The chlorophyll content decreased as EC 

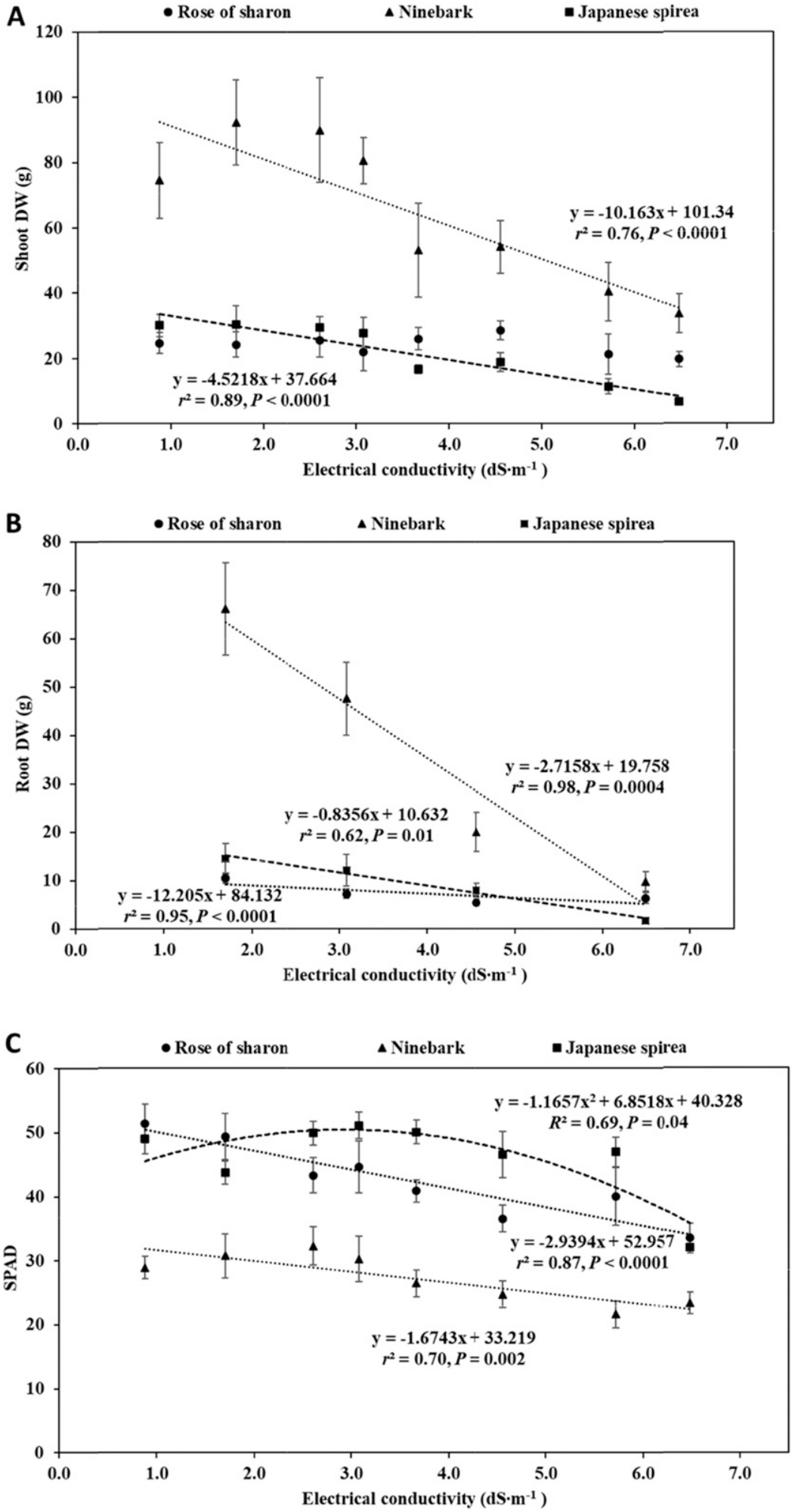

Fig. 2. The shoot dry weight $[\mathrm{DW}(\mathrm{A})]$, root $\mathrm{DW}(\mathrm{B})$, and relative chlorophyll content [SPAD $(C)$ ] of rose of sharon, ninebark, and japanese spirea irrigated for 11 weeks with saline solutions at eight different electrical conductivity levels using a near-continuous gradient dosing system. Linear and quadratic trend analyses were used; $1 \mathrm{dS} \cdot \mathrm{m}^{-1}=1 \mathrm{mmho} / \mathrm{cm}, 1 \mathrm{~g}=0.0353 \mathrm{oz}$.

levels increased (Fig. 2C). There was a linear correlation $(P<0.0001)$ between SPAD readings of rose of sharon and EC levels. The SPAD readings of rose of sharon plants irrigated with saline solutions at an of EC $6.5 \mathrm{dS} \cdot \mathrm{m}^{-1}$ was reduced by $35 \%$ compared with the control. Liu et al. (2017) also found that the SPAD readings of 'ILVOPS' rose of sharon irrigated with a saline solution at an EC of $10 \mathrm{dS} \cdot \mathrm{m}^{-1}$ decreased significantly compared with irrigation water at an EC of 5.0 and $1.2 \mathrm{dS} \cdot \mathrm{m}^{-1}$. The SPAD readings of ninebark decreased linearly $(P=0.002)$ when EC levels increased, with a $19 \%$ reduction in plants irrigated with saline solutions at an EC of $6.5 \mathrm{dS} \cdot \mathrm{m}^{-1}$ when compared with the control. The SPAD readings of japanese spirea had a quadratic correlation $(P=0.04)$ with EC levels and declined $\approx 35 \%$ at an EC of $6.5 \mathrm{dS} \cdot \mathrm{m}^{-1}$ compared with the control. Similarly, Wang et al. (2019) found that saline solutions at an EC of 3.0 and $6.0 \mathrm{dS} \cdot \mathrm{m}^{-1}$ did not affect the SPAD readings of 'Galen', 'NCSXl', and 'Tracy' japanese spirea, but reduced the SPAD readings of 'Minspi', 'NCSX2', 'SMNSJMFP', and 'Yan' japanese spirea. AcostaMotos et al. (2017) suggested that plants could acclimate to $\mathrm{NaCl}$ conditions by increasing the chlorophyll content to protect the photosynthesis process. However, this was not the case in the current and previous studies (Cai et al., 2014; Liu et al., 2017; Sun et al., 2015), which showed consistently that relative chlorophyll content decreased with increasing EC levels.

Gas exchange. Salinity had effects on leaf gas exchange, including $P_{n}$ and transpiration rate (Fig. 3). There was a linear correlation $(P<$ $0.001)$ between EC levels of irrigation water and $P_{n}$ of rose of sharon. Compared with those plants at an EC of $1.7 \mathrm{dS} \cdot \mathrm{m}^{-1}$, saline solutions at an EC of $6.5 \mathrm{dS} \cdot \mathrm{m}^{-1}$ reduced significantly the $\mathrm{P}_{\mathrm{n}}$ of rose of sharon by $52 \%$. The $P_{n}$ of 'ILVOPS' rose of sharon decreased $41 \%$ and $85 \%$ by saline solutions at an EC of 5.0 and EC $10.0 \mathrm{dS} \cdot \mathrm{m}^{-1}$ at 5 weeks and $47 \%$ and $97 \%$ at 9 weeks, respectively (Liu et al., 2017). Santiago et al. (2000) also reported that increasing salinity levels reduced the $\mathrm{CO}_{2}$ assimilation of sea hibiscus (Hibiscus tiliaceus). The $\mathrm{P}_{\mathrm{n}}$ of ninebark decreased linearly $(P=$ $0.01)$ as EC levels of irrigation water increased (Fig. 3). Ninebark irrigated with saline solutions at an EC of 6.5 $\mathrm{dS} \cdot \mathrm{m}^{-1}$ decreased its photosynthesis by $21 \%$ compared with those irrigated at an EC of $1.7 \mathrm{dS} \cdot \mathrm{m}^{-1}$. According to 

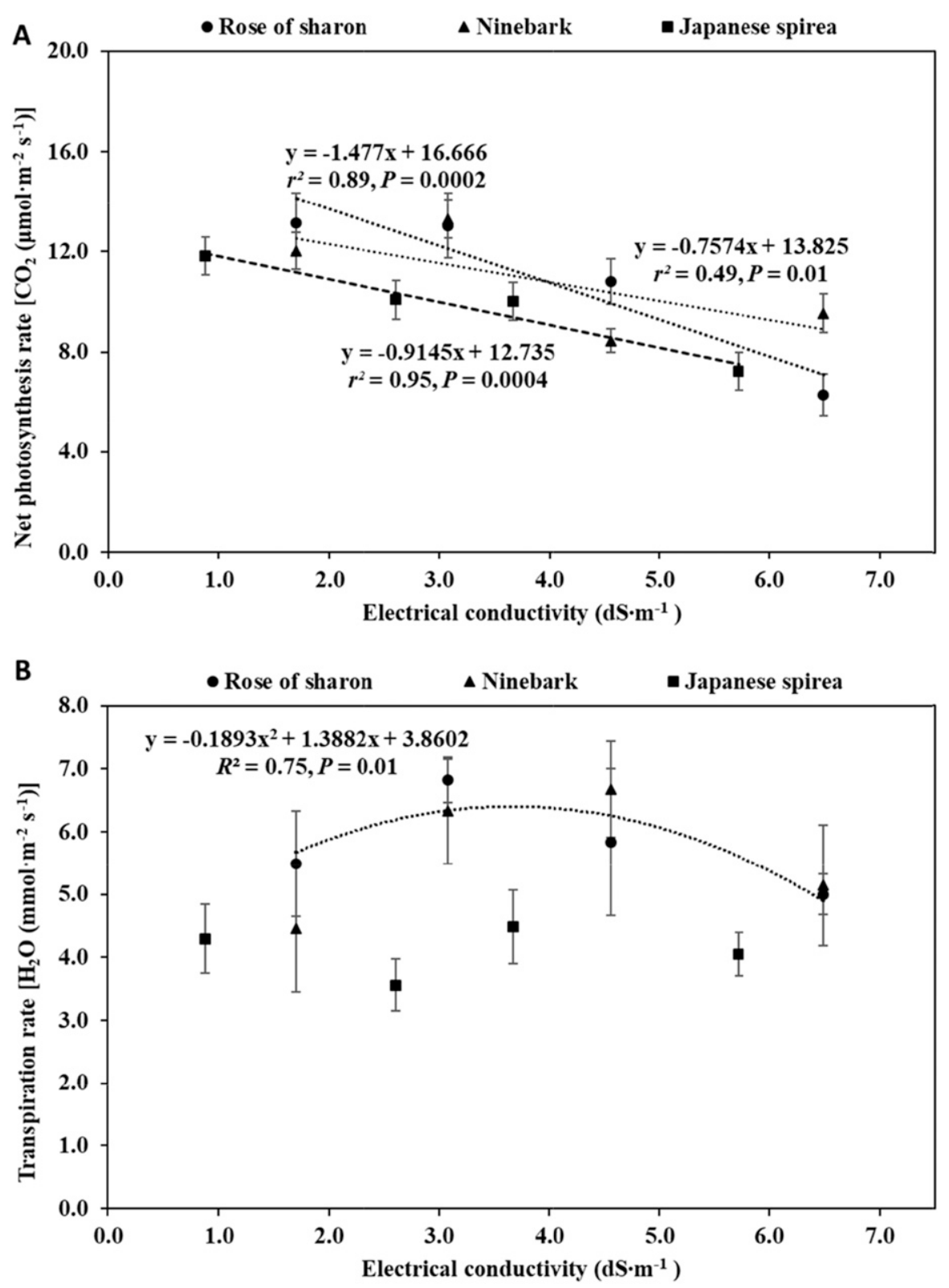

Fig. 3. Net photosynthesis rate [carbon dioxide $\left.\left(\mathrm{CO}_{2}\right)(\mathrm{A})\right]$ and transpiration rate [water $\left(\mathrm{H}_{2} \mathrm{O}\right)(\mathrm{B})$ ] of rose of sharon, ninebark, and japanese spirea irrigated for 11 weeks with saline solutions at eight different electrical conductivity (EC) levels using a near-continuous gradient dosing system. Rose of sharon and ninebark plants irrigated with saline solutions at an EC of 1.7, 3.1, 4.6, and $6.5 \mathrm{dS} \cdot \mathrm{m}^{-1}$ were used for the measurements; but, japanese spirea plants irrigated with saline solutions at an EC of $0.9,2.6,3.7$, and $5.7 \mathrm{dS} \cdot \mathrm{m}^{-1}$ were used because all plants died at an EC of $6.5 \mathrm{dS} \cdot \mathrm{m}^{-1}$. Linear and quadratic trend analyses were used; 1 $\mathrm{dS} \cdot \mathrm{m}^{-1}=1 \mathrm{mmho} / \mathrm{cm}, 1 \mathrm{~m}^{2}=0.0929 \mathrm{ft}^{2}$.

the study by Xu et al., (2018), the $P_{n}$ of asian ninebark (Physocarpus amurensis) and 'Diabolo' ninebark (P. opulifolius) decreased when plants were irrigated with 50,100 , and 200 $\mathrm{mmol} \cdot \mathrm{L}^{-1} \mathrm{NaCl}$ water $(\approx 4.6,7.3$, and $14.6 \mathrm{dS} \cdot \mathrm{m}^{-1}$, respectively). 'Diabolo' ninebark was more sensitive to high salinity concentrations. For japanese spirea, a linear correlation $(P=$ 0.0004 ) between $P_{n}$ and EC levels of irrigation water was observed, with a 39\% reduction in plants irrigated with saline solutions at an EC of 5.7 $\mathrm{dS} \cdot \mathrm{m}^{-1}$ compared with those at an EC of $0.9 \mathrm{dS} \cdot \mathrm{m}^{-1}$ (Fig. 3). Wang et al. (2019) also found that the $P_{n}$ of japanese spirea was reduced by $41 \%$ to $56 \%$ at an EC of $6.0 \mathrm{dS} \cdot \mathrm{m}^{-1} \mathrm{com}$ pared with an EC of $1.2 \mathrm{dS} \cdot \mathrm{m}^{-1}$. In our study, a quadratic correlation $(P=$ 0.01 ) was observed between EC levels of irrigation water and the transpiration rate of rose of sharon. However, no correlation was observed between EC levels of irrigation water and the transpiration rate of ninebark and japanese spirea (Fig. 3 ). Liu et al. (2017) reported that the transpiration rate of 'ILVOPS' rose of sharon was reduced when irrigated with saline solutions at an EC of 5.0 or $10.0 \mathrm{dS} \cdot \mathrm{m}^{-1}$ at 5 and 9 weeks. The negative effect of salinity on the gas exchange of different plants has been revealed in different studies (Cai et al., 2014; Liu et al., 2017; Sun et al., 2015). These might result from the salt-induced water deficit that decreases turgor pressure and inhibits plant photosynthesis (Taiz et al., 2015). It might also be noted that increased ion concentrations in plant leaf tissue could cause ion toxicity that damages plant photosynthesis systems and reduces photosynthesis (Taiz et al., 2015).

\section{Conclusions}

In this study, the NCGD system provided continuous EC levels with little variance. As EC levels increased, saline irrigation water did not affect the visual quality and shoot DW of rose of sharon. We were not able to define the salinity threshold for rose of sharon. These results indicate that rose of sharon may have a salinity threshold greater than an EC of $6.5 \mathrm{dS} \cdot \mathrm{m}^{-1}$. Saline irrigation water at increasing EC levels reduced the visual quality of ninebark quadratically and shoot DW linearly. The salinity threshold was found at an EC of $5.4 \mathrm{dS} \cdot \mathrm{m}^{-1}$, at which $50 \%$ of shoot DW was lost. Japanese spirea was sensitive to salinity levels in our study, with quadratic or linear correlation for visual quality and shoot DW, respectively. The salinity threshold of japanese spirea was determined to be at an EC of $4.6 \mathrm{dS} \cdot \mathrm{m}^{-1}$. Japanese spirea was more susceptible to salinity stress than ninebark.

\section{Literature cited}

Acosta-Motos, J.R., M.F. Ortuño, A. Bernal-Vicente, P. Diaz-Vivancos, M.J. Sanchez-Blanco, and J.A. Hernandez. 2017. Plant responses to salt stress: Adaptive mechanisms. Agronomy 7:18.

Aragues, R., E. Playa, R. Ortiza, and A. Royo. 1999. A new drip-injection irrigation system for crop salt tolerance evaluation. Soil Sci. Soc. Amer. J. 63:1397-1404. 
Aragues, R., A. Royo, and J. Faci. 1992. Evaluation of a triple line source sprinkler system for salinity crop production studies. Soil Sci. Soc. Amer. J. 56:377-383.

Cai, X., Y. Sun, T. Starman, C. Hall, and G. Niu. 2014. Response of 18 EarthKind ${ }^{\circledR}$ rose cultivars to salt stress. HortScience 49:544-549.

Curtis, P.S. and A. Läuchli. 1987. The effect of moderate salt stress on leaf anatomy in Hibiscus cannabius (Kenaf) and its relation to leaf area. Amer. J. Bot. 74: 538-542.

De Malach, Y., J. Ben-Asher, M. Sagi, and A. Alert. 1996. Double-emitter source (DES) for irrigation experiments in salinity and fertilization. Agron. J. 88:987990.

Gibson, J.L. 2007. Nutrient deficiencies in bedding plants: A pictorial guide for identification and correction. Ball Publishing, Batavia, IL.

Gils, J., C. Chong, and G. Lumis. 2005. Response of container-grown ninebark to crude and nutrient-enriched recirculating compost leachates. HortScience 40:1507-1512.

Hawks, A., G. Cardon, and B. Black. 2009. Comparing strawberry salt toler- ance using a low volume near-continuous gradient dosing system. J. Amer. Pomol. Soc. 63:136-141.

Jull, L.G. 2009. Winter salt injury and salt-tolerant landscape plants. Univ. Wisconsin Coop. Ext. A3877.

Liu, Q., Y. Sun, G. Niu, J. Altland, L. Chen, and L. Jiang. 2017. Morphological and physiological responses of ten ornamental taxa to saline water irrigation. HortScience 52:1816-1822.

Marosz, A. 2004. Effect of soil salinity on nutrient uptake, growth and decorative value of four ground cover shrubs. J. Plant Nutr. 27:977-989.

Munns, R. 2002. Comparative physiology of salt and water stress. Plant Cell Environ. 25:239-250.

Munns, R. and M. Tester. 2008. Mechanisms of salinity tolerance. Annu. Rev. Plant Biol. 59:651-681.

Xu, N., H. Zhang, H. Zhong, Y Wu, J. Li, L. Xin, Z. Yin, W. Zhu, Y. Qu, and G. Sun. 2018. The response of photosynthetic functions of $f_{1}$ cutting seedlings from Physocarpus amurensis maxim $(+) \times$ Physocarpus opulifolius 'Diabolo' ( $1 \hat{)}$ and the parental seedlings to salt stress. Front. Plant Sci. 9:714.

Santiago, S.L., T.S. Lau, P.J. Melcher, O.C. Steele, and G. Goldstein. 2000. Morphological and physiological responses of Hawaiian Hibiscus tiliaceus populations to light and salinity. Intl. J. Plant Sci. 161:99-106.

Sun, Y., G. Niu, and C. Perez. 2015. Relative salt tolerance of seven Texas

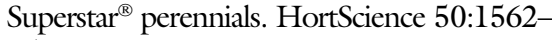
1566.

Taiz, L., E. Zeiger, I.M. Møller, and A. Murphy. 2015. Plant physiology and development. 6th ed. Sinauer Associates, Sunderland, MA.

Valdez-Aguilar, L., C.M. Grieve, A. Razak-Mahar, M.E. McGiffen, and D.J. Merhaut. 2011. Growth and ion distribution is affected by irrigation with saline water in selected landscape species grown in two consecutive growing seasons: Spring-summer and fall-winter. HortScience 46:632-642.

Wang, Y., L. Li, Y. Sun, and X. Dai. 2019. Relative salt tolerance of seven japanese spirea cultivars. HortTechnology 29:1-7. 